\title{
The Impact of Energy Consumption and Economic Development on Changes in China's Provincial-Level Environmental Quality*
}

\author{
Wan-Ping Yang ${ }^{1,2}$, Ban Lan $^{1}$, Kunshi Zheng ${ }^{1}$ \\ ${ }^{1}$ School of Economics and Finance, Xi' an Jiaotong University, Xi'an, China \\ ${ }^{2}$ School of Public Policy administration, Xi'an Jiaotong University, Xi' an, China \\ Email: wanpingyang@mail.xjtu.edu.cn,banlan.2007@stu.xjtu.edu.cn
}

Received September 18, 2012; revised October 16, 2012; accepted November 10, 2012

Copyright (C) 2013 Wan-Ping Yang et al. This is an open access article distributed under the Creative Commons Attribution License, which permits unrestricted use, distribution, and reproduction in any medium, provided the original work is properly cited.

\begin{abstract}
Based on the features of energy consumption and economic development in China, since single pollutant can hardly express the situation of environmental pollution, we propose a pollution emissions index that can reflect the level of environmental quality, measure China's 28 provinces' environmental quality from 1995 to 2010 with a dynamic objective evaluation method based on the overall differences first time. Then panel data model was applied to analyze the impact of energy consumption and economic development on China's and regional environmental quality. The results showed that emissions index varied among different regions and there was great potential for emission reduction; there was a significant positive correlation between emissions index and scale of economies and industrial structure; there was a negative correlation between emissions index and energy efficiency, energy prices and degree of opening up. Policy implications are as follows: 1) reduction policies should be made in line with local conditions; 2) the eastern region is the key areas of emissions reduction; 3 ) to improve energy efficiency is an important way to reduce emissions.
\end{abstract}

Keywords: Energy Consumption; Economic Development; Dynamic Comprehensive Evaluation; Pollution Emissions Index; Panel Data Model

\section{Introduction}

In the past 30 years, China has experienced sustained and rapid economic growth, which is partly simulated by the extensive mode of economic growth aimed to GDP onesided. However, a series of problems such as energy shortage and environmental pollution has been brought meanwhile. Faced with a "dilemma" between energy and development in the traditional sense to a "tripartite tangle" of energy, environment and development, the state

\footnotetext{
${ }^{*}$ Supported by: the major project of State Social Sciences Fund: countermeasures study of the transformation of economic development in China to promote scientific development (11AZD001); the Program for New Century Excellent Talents in University of Ministry of Education of China: the research on the index evaluation system of Chinese low-carbon economy (NCET-10-0683); the youth programs of State Social Sciences Fund: energy consumption, pollution emissions and sustainable economic development in China (10CJL034); China's Post-doctoral Fund: the transformation and sustainability of economic development in China in "tripartite tangle" society (2012M521752); the special fund of state-run university's basic research funding, the research plan supporting new teachers and the third subproject of 211 in Xi'an Jiaotong University: the national key subjects of industrial economics oriented to the research of strategic industrial development.
}

proposed the strategic goal of building a "two-oriented society" timely, trying to achieve the harmony and unity of the three by integrating. In the "Eleventh Five-Year Plan", it is clearly proposed that energy consumption intensity (ton of standard coal per ten thousand Yuan Dynasty of GDP) should be reduced by $20 \%$ and major pollutants emissions should be cut $10 \%$.

Economic development must not stop in spite of energy consumption and environmental pollution. Since Chinese reform and opening up, energy consumption has increased significantly in the rapid economic growth: in 2010 it is 5.69 times as that of 1978 . However, energy consumption intensity (in current price) dropped significantly from 15.68 tons of standard coal in 1978 to 0.81 tons of standard coal in 2010 and the proportion of coal in total energy consumption fell by 2.7 percentage point. Meanwhile the rate of environmental pollutants emissions decreased as well. These indicate it is possible that achieving the strategy of sustainable development through improving energy efficiency and energy consumption structure in the constraint of economic growth. 
To control the regional pollution is based on a clear understanding of the regional pollution characteristics, which can provide a theoretical basis and macro-control ideas on coordinating regional economic development, energy consumption and environmental protection in China. Therefore, we will correctly understand and accurately evaluate the environmental pollution in different areas of China and study the influence of energy consumption structure, energy consumption intensity, energy prices, economic growth and economic structure on the environmental pollution in different regions of China. The study can help to find out the potential cause of the difference of the environmental pollution in different areas, provide a scientific basis on formulating the effective measures of reducing pollution emissions, and then contribute to the long-term sustainable economic development of China. Overall, it is undoubtedly significant in both theory and practice to correctly.

\section{Literature Review}

Foreign scholars studied the impact of economic development and energy consumption on the environmental quality earlier. Hettige et al. (2000) [1] calculate the effect of economic scale, industrial structure and technology on the BOD of both developed and developing countries. Zhang (2000) [2] calculates the effect of the proportion of fossil energy in total energy consumption, the ratio of fossil energy consumption to non-fossil, productivity and economic scale on the carbon dioxide emissions of China. Antweiler et al. (2001) [3] calculate the effect of economic scale, industrial structure, technology and trade on global sulfur dioxide emissions. Stern (2002) [4] believes that the expansion of economic scale has a positive effect on the increase of global sulfur dioxide emissions while it has a negative effect on scientific and technological progress by non-linear pollution decomposing model and regression analysis based on the panel data of 64 countries' sulfur dioxide emissions in 1973-1990. Dinda (2004) [5] considers that there are many reasons for environmental degradation, while the main factors are the expansion of economic scale, changes in industrial structure as well as scientific and technological progress.

Domestic scholars researched more deeply into the issues of economic development, energy consumption and environmental quality from various angles. Yang Fu-xia, Nie Hu-ling, Yang Mian (2010) [6] measure the composite environmental pollution index of China in 1986-2007 by selecting three indictors: the total wastewater emissions, industrial exhaust emissions and industrial solid waste emissions; then study the effect of industrial structure, environmental policy, the level of urbanization and FDI on the composite environmental pollution index of China via introducing the generalized impulse response function to analysis of VEC model. Ding Huan-feng, Li Pei-yi (2010) [7] quantitatively and comparatively analyze the overall patterns of regional pollution, the difference of regional pollution control efficiency and the structural features of regional pollution throughout the country and four regions due to the statistical data of economic development and six pollution indicators including industrial wastewater emissions and industrial exhaust emissions of all the regions in China in 19982008. Wang Jun-song, He Can-fei (2010) [8] decompose and analyze the carbon dioxide emissions of China in 1990-2007 through the LMDI model (Logarithmic Mean Divisia Index). He Jie (2010) [9] establishes a fourequation simultaneous system and estimates the model based on the panel data of 29 provinces' industrial sulfur dioxide emissions in China in 1973-1990; it turns out that exports and imports of manufactured goods play a completely opposite role in the decision of industrial sulfur dioxide emissions. Li Guo-zhang, Jiang Jin-rong, Zhou Cai-yu (2009) [10] consider total factor energy efficiency, industrial structure and energy structure are the main factors that affect the environmental pollution of China. He Zheng-xia, Xu Shi-chun (2009) [11] characterize environmental pollution with "Industrial three wastes"; then discover that export deteriorates the environment at some level and meanwhile export growth is the Granger cause of the increase in environmental pollution. $\mathrm{Yu}$ Mei-xia, Zhou Min-liang (2009) [12] quantitatively analyze the main factors that influence the change of each province's environmental quality in China by principal component analysis due to the data of water, atmospheric and solid pollution. Lin Bo-qiang, Jiang Zhu-jun (2009) [13] analyze the main factors that impact the per capita carbon dioxide emission of China by LMDI and the model of STIRPA; then they believe except per capita income, all of the factors including energy consumption intensity, industrial structure and energy consumption structure have a significant effect, especially industrial energy consumption intensity. Yang Wan-ping, Yuan Xiao-ling (2008) [14] calculate the environmental pollution index of China in 1982-2006 based on six environmental pollution indictors, which can represent the overall conditions of environmental pollution; they research into the long term and dynamic impact of foreign trade and FDI on the environmental pollution in China by the impulse response function of VAR model and variance decomposition analysis. The analysis results show that FDI and import trade improved environmental quality while export trade deteriorated the environmental quality in China. Yu Feng, Qi Jian-guo, Tian Xiao-lin (2006) [15] characterize the level of environmental pollution with sulfur dioxide emissions; regression analysis based on the panel data of China's 28 provinces, municipalities and autonomous regions in 1994-2004 indicates that the 
expansion of economic scale as well as the changes of industrial structure and energy consumption structure exacerbated environmental pollution while the improvement of productivity as well as the innovation and promotion of environmental technologies reduced environmental pollution.

It can be seen that the above embrace both direct and indirect way, in which economic development and energy consumption affect environment. However, when the mechanism of action how economic development and energy consumption impact environment studied, there are at least two issues: 1) most literatures characterize environmental quality with single indicator or multiple single indicators. Single indicator is difficult to represent the pressure on the environment (Grossman and Krueger, 1991 [16]), integrating all the indictors that influence environmental pollution into the form of single index is required. Although some researches introduce the composite environmental indicators (Wang Xi-qin, Li Fen, 2005 [17]; Shen Feng, 2008 [18]; Yang Wan-ping, Yuan Xiao-ling, 2009 [19]), which is a step forward than single indicator, yet there is a great deal of subjectivity and limitations because of the evaluation object selected only from a single region or the weights determined by experts scoring method. Yang Long, Hu Xiao-zhen (2010) [20] and Shen Neng (2010) [21] comprehensively evaluate environmental quality of province region by improved entropy method, but there are at least two debatable problems: a) there is duplication of selecting indicators, because they ignore the fact that industrial exhaust emissions include industrial soot emissions, industrial dust emissions and industrial sulfur dioxide emissions; b) inter-provincial pollution evaluation is not comparable, since entropy method is only suitable for the analysis of time series or cross-sectional data, then the data of panel analysis is not comparable among province. 2) Most studies limit to single or sporadic several elements and lack of comprehensiveness and systematization.

Owing to these, we try to expand existing literatures on the basis of existing achievements: above all, we set up a comprehensive indicator of environmental qualitythe environmental pollution index. Since we introduce a dynamic objective evaluation method in view of the overall differences to evaluate the environmental quality of China's provinces at different times, the index can maximize the representation of the overall environmental quality in order to solve the dilemma that the empirical research based on a single or a few independent environmental pollution indicators can not reveal the overall environmental quality. Next, in the perspective of economic structure and energy, we comprehensively and systematically study the main factors affecting environmental quality by panel data model so as to find a reasonable scientific basis for formulating environmental policy and explore the focal point of emission reduction.

\section{The Trend of Environmental Quality}

\subsection{Indicator Selection and Data Sources}

Environmental quality can be measured from multiple dimensions. Taking the availability of data into account, the paper selects the indicators of pollution emissions; considering the impact of three pollutants including wastewater, exhaust and solid waste, the paper consolidates them to form a pollution emissions index that can reflect the level of environmental quality. Because wastewater and exhaust is difficult to be stored, emissions are adopted. Since tremendous amount of solid waste is stored instead of being discharged, production is employed. Seeing that the monitoring and statistics of China's environmental quality is mainly on the base of industrial pollutants statistics, finally we pick industrial wastewater emissions, industrial exhaust emissions and industrial solid waste production as indictors that influence the comprehensive evaluation index of environmental quality. The index simultaneously considers the impact of gaseous, solid and liquid emissions on the environmental quality, which is able to report environmental quality better. Therefore, we can directly compare the overall environmental quality of various regions. Data sources from "China Statistical Yearbook" and "China Statistical Yearbook of Environment" in the relevant years.

\subsection{Dynamic Comprehensive Evaluation Method of Pollution Emissions Index}

Evaluation of environmental quality should be based on objective fact to avoid the interference of subjective factors. Thence, we choose dynamic objective comprehensive evaluation-vertical and horizontal scatter degree method [22], which is suitable for panel data. It is the first time that the method is used to evaluate environmental quality. The main steps to evaluate the overall environmental quality are:

1) Standardization of data. Since different indicators have different dimensions and units, which give rise to incommensurability, so as to eliminate it we should turn evaluation indicators into dimensionless in the first place. Suppose $\left\{x_{i j}\left(t_{k}\right)\right\}$ as the numerical value of indicator $j$ of sample $i$ at time

$$
\begin{gathered}
\left.t_{k}(i=1,2, \cdots, m ; j=1,2, \cdots, n ; k=1,2, \cdots, T)\right) . \\
x_{i j}^{\prime}\left(t_{k}\right)=\frac{x_{i j}\left(t_{k}\right)-\overline{x_{j}\left(t_{k}\right)}}{s_{j}\left(t_{k}\right)}
\end{gathered}
$$

In the formula: $x_{i j}^{\prime}\left(t_{k}\right)$ is the numerical value of standardization; $i$ is province; $j$ is pollution indicator; $x_{i j}\left(t_{k}\right)$ is the original numerical value; $x_{j}\left(t_{k}\right), s_{j}\left(t_{k}\right)$ are mean and standard deviation of indicator $j$ at time $t_{k}$. 
2) Calculate real symmetric matrix $H_{k}$ : $H_{k}=X_{k}^{\tau} X_{k}(k=1,2, \cdots, T)$. In the formula:

$$
X_{k}=\left[\begin{array}{ccc}
x_{11}^{\prime}\left(t_{k}\right) & \cdots & x_{1 m}^{\prime}\left(t_{k}\right) \\
\vdots & \ddots & \vdots \\
x_{n 1}^{\prime}\left(t_{k}\right) & \cdots & x_{n m}^{\prime}\left(t_{k}\right)
\end{array}\right], k=1,2, \cdots, T
$$

3) Find maximized eigenvalue and standard eigenvectors $\lambda^{\prime}$ corresponding to it. And,

$$
H=H_{1}+H_{2}+\cdots+H_{k}(k=1,2, \cdots, T)
$$

4) Calculate weight vector $\omega_{j}$ : Normalize standard eigenvectors $\lambda^{\prime}$ to certain combined $\omega_{j}$.

5) Calculate the numerical value of environmental pollution index $P_{i}\left(t_{k}\right)$ :

$$
P_{i}\left(t_{k}\right)=\sum_{j=1}^{n} \omega_{j} x_{i j}^{\prime}\left(t_{k}\right), k=1,2, \cdots, T ; i=1,2, \cdots, m
$$

In the formula: $P_{i}\left(t_{k}\right)$ is the pollution index that indicates the environmental quality of province $i$ at time $t_{k}, \omega_{j}$ is the weighs of pollution emission $j$. The larger the index, the worse the environmental quality.

\subsection{The Evolution of Environment Quality}

The study covers all the regions of China except Tibet, Taiwan, Hong Kong and Macao. Moreover, in order to maintain the consistency of the statistical coverage of data, we classify the data of Hainan Guangdong and the data of Chongqing Sichuan, thus there are 28 provinces, municipalities and autonomous regions altogether (hereinafter referred to as provinces).

Calculate the weight coefficient corresponding to maximized eigenvalue due to symmetric matrix $H$. Then we can obtain the numerical value of the comprehensive evaluation of the environmental quality in 28 provinces-pollution emissions index $P_{i}\left(t_{k}\right)$. For the purpose of visual comparison and generality, we process the translation of $P_{i}\left(t_{k}\right)$, which is $\left(P_{i}\left(t_{k}\right)+2\right)$ (Table 1).

From the regional perspective ${ }^{1}$ (east, central region and west) (Figure 1), the mean of pollution emissions index of east in 1995-2010 is in an overall upward trend; while that of central region is exactly opposite, in a gradual downward trend; the index of west in 1995-2010 is in an overall upward trend as well, it is noteworthy that the trend of pollution is severely exacerbated after 2000 .

Comparing the mean of pollution emissions index of different regions in China in sample period of 1995-2010,

\footnotetext{
${ }^{1}$ East: 10 provinces including Beijing, Tianjin, Hebei, Liaoning, Shanghai, Jiangsu, Zhejiang, Fujian, Shandong and Guangdong. Central region: 8 provinces including Shanxi, Jilin, Heilongjiang, Anhui, Jiangxi, Henan, Hubei and Hunan. West: 10 provinces including Sichuan, Guizhou, Yunnan, Shaanxi, Gansu, Qinghai, Ningxia, Xinjiang, Guangxi and Inner Mongolia.
}

we can see: the mean of pollution emissions index of east, central region and west are followed by $2.2711,2.2175$ and 1.5488 in sample period of 1995-2010, the mean of east and central region is higher than that of China and much higher than that of west. Single provinces whose numerical values of pollution emissions index are higher than the sample mean of all provinces are followed by Hebei (3.8212), Jiangsu (3.4260), Jilin (3.4194), Liaoning (3.4066), Shanxi (3.1711), Heilongjiang (2.6472), Henan (2.6263), Shandong (2.5830), Zhejiang (2.2650), Hubei (2.0793), Ningxia (2.0210) and other provinces.

\section{Data Sources and Model Specification}

\subsection{Data Sources}

The paper applies the panel data of China's 28 provinces in 1995-2010. Data sources from "China Statistical Yearbook" and "China Statistical Yearbook of Environment" in the relevant years. Explained variable is the pollution emissions index that represents the environmental quality; on the basis of China's current historical period and its real situation, explanatory variables include: 1) Economic scale (GDP). Characterize it with GDP of each province, set 1990 as the base year and commodity retail price index lay the foundation of GDP decorator; 2) Industrial Structure (SC). Use each the proportion of (regional) secondary industry output in (regional) GDP to indicate SC; 3) Trade Openness (OPE). Express it as the proportion of (regional) import and export value (in RMB) in (regional) GDP; 4) Energy Efficiency (EE). It equals reciprocal of energy consumption intensity; 5) Energy Price (EP). Express it as Purchasing Price Index of Raw Material, Fuel and Power (PPIRM) and set 1990 as the base year.

Considering that logarithm can eliminate heteroscedasticity of data and maintain the characteristic of data, in the paper we actually analyze logarithmic value of each variable. Therefore, we construct an empirical model containing seven explanatory variables.

$$
\begin{aligned}
& \operatorname{Ln} P_{i, t}=C_{i, t}+\beta_{1} \operatorname{Ln} \mathrm{GDP}_{i, t}+\beta_{2} \operatorname{LnSC}_{i, t}+\beta_{3} \operatorname{Ln} \mathrm{OPE}_{i, t} \\
& +\beta_{4} \operatorname{Ln} \mathrm{EE}_{i, t}+\beta_{5} \operatorname{Ln} \mathrm{EP}_{i, t}+\varepsilon_{i, t}
\end{aligned}
$$

In the formula: $i, t$ denote the corresponding value of different provinces in different period; $\varepsilon_{i j}$ is stochastic error term and obey normal distribution.

\subsection{Model Specification}

Because of the data in the paper is 28 provincial crosssectional data of year 1995-2010, they can be regarded as Pool Data as well as Panel Data. Pool Data assumes each cross-section independent but obey different distribution while Panel Data is obtained by annually repeating the 
Table 1. Pollution emissions index of 28 provinces in China (1995-2010).

\begin{tabular}{|c|c|c|c|c|c|c|c|c|c|c|c|c|c|c|c|c|c|}
\hline Year & 1995 & 1996 & 1997 & 1998 & 1999 & 2000 & 2001 & 2002 & 2003 & 2004 & 2005 & 2006 & 2007 & 2008 & 2009 & 2010 & $\begin{array}{l}\text { Mean } \\
\text { value }\end{array}$ \\
\hline Beijing & 3631 & 1.3970 & 1.4318 & 1.3250 & 1.2642 & 1.2384 & 1.1693 & 1.0793 & 1.0247 & 1.0533 & 1.0389 & 1.0287 & 10005 & 0.9221 & 0.9013 & 1 & 1401 \\
\hline Tianjin & 9 & 08 & 2 & 4 & 4 & 998 & 698 & 108 & 092 & 75 & 77 & 4 & 21 & 63 & 98 & 6 & 251 \\
\hline Hebei & 3.3898 & 3.4090 & 3.4599 & 3.7402 & 3.5501 & 3.4005 & 3.5725 & 3.5163 & 3.6198 & 4.3034 & 4.1424 & 4.1323 & 4.2968 & 3.8837 & 4.2783 & 4.4443 & 3.8212 \\
\hline Liaoning & 3.1262 & 3.2406 & 3.4038 & 3.3887 & 3.3997 & 3.5640 & 3.5625 & 3.3956 & 3.3953 & 3.3782 & 3.4210 & 3.3262 & 3.3668 & 3.5027 & 3.5461 & 3.4880 & 3.4066 \\
\hline Shanghai & 554 & 2.1670 & 2.1034 & 9387 & 1.8842 & 1.8789 & 1.8781 & 1.8215 & 1.7304 & 6846 & 1.5358 & 1.4513 & 1.3821 & 3681 & 3027 & 3888 & 17204 \\
\hline Jiangsu & 3.5882 & 3.5483 & 3.1974 & 3.2613 & 3.3493 & 3.3076 & 3.8274 & 3.7610 & 3.5165 & 3.5166 & 3.5196 & 3.5365 & 3.1593 & 3.1799 & 3.2048 & 3.3425 & 4260 \\
\hline Zhejiang & 1.7556 & 1.6996 & 1.8046 & 2.1290 & 2.1663 & 2.3438 & 2.4852 & 2.4540 & 2.5161 & 2.4305 & 2.4071 & 2.3837 & 2.3920 & 2.3852 & 2.4154 & 2.4720 & 2650 \\
\hline Fujian & 2939 & 1.2452 & 1.1789 & 1.2301 & 1.3735 & 1.5468 & 2.0177 & 1.8642 & $1770 ?$ & 1.8437 & 1.8963 & 1.8557 & 10 & 10784 & 20100 & 3 & 16805 \\
\hline Shandong & 645 & 301 & 3407 & 2.5281 & 2.5997 & 2.6132 & 2.5126 & 2.6817 & 2.6069 & 15 & 2.7150 & 2.5 & 2.64 & 2.7055 & 6286 & 2.4242 & 5830 \\
\hline Guangdong & 2.0862 & 2.1787 & 2.1989 & 1.9215 & 1.8459 & 1.7919 & 1.7335 & 1.6737 & 1.6176 & 1.5004 & 1.4451 & 1.4521 & 1.4040 & 1.4017 & 1.4631 & 1.3972 & 1.6945 \\
\hline Shanxi & 1.5806 & 1.5 & 1.5561 & 1.3870 & 1.4178 & 1.3731 & 1.3339 & 960 & 08 & 42 & 1.3425 & 1.3047 & 2782 & 1.2667 & 1.2931 & 10 & 688 \\
\hline Jilin & 0467 & $4 .($ & 4.10 & 3.7694 & 3.7022 & 3.5392 & 3.2648 & 3.1707 & 3.1742 & 2.8023 & 3.2010 & 3.36 & 2.90 & (נ. & 2.93 & 3 & 3.419 \\
\hline Heilongjiang & 2.3237 & 2.4008 & 2.3907 & 2.7669 & 2.6701 & 2.7634 & 2.6224 & 2.7911 & 3.0325 & 2.6700 & 2.6711 & 2.6636 & 2.6383 & 2.7789 & 2.5701 & 2.6011 & 2.6472 \\
\hline Anhui & 2.0839 & 2.0079 & 2.0821 & 1.8649 & 1.8641 & 1.8209 & 1.8704 & 1.8485 & 1.7848 & 1.7094 & 1.7033 & 1.7681 & 1.8968 & 2.0229 & 2.0214 & 1.8342 & 1.8865 \\
\hline Jiangxi & 1.9550 & 1.9780 & 1.8205 & 1.7051 & 1.6507 & 1.7891 & 1.6568 & 1.8556 & 1.8894 & 1.7963 & 1.7763 & 1.7976 & 1. & .7634 & 2 & 1 & 1 \\
\hline Henan & 2 & 2. & 65 & 2 & 39 & 2.66 & 2 & 2 & 2 & 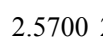 & 2.6 & 2 & 2 & 2 &  & 2 & 20 \\
\hline Hubei & 2.3013 & 2.3868 & 2.3021 & 2.3446 & 2.3732 & 2.2925 & 2.0634 & 2.0807 & 2.0029 & 2.0120 & 1.9103 & 1.8913 & 1.7684 & 1.8035 & 1.8168 & 1.9186 & 2.0793 \\
\hline Hunan & 2.2156 & 2.2447 & 2.1723 & 2.2196 & 2.0632 & 1.9800 & 1.8827 & 1.8482 & 1.9086 & 1.9056 & 1.8112 & 1.6567 & 1.7370 & 1.6786 & 1.7548 & 1.6558 & 1.9209 \\
\hline Inner Mons & 1. & 1.42 & 1.4 & 1.4328 & 1.4189 & 1.4056 & 1.3723 & 1.44 & 1.43 & 1. & 1.5415 & 1.4922 & 1.5 & 1.62 & 1.58 & 1 & 14 \\
\hline Guangxi & 1.3599 & 1.3554 & 1. & 1.3339 & 1.3003 & 1.2752 & 1.1634 & 1.1840 & 91 & 1.1923 & 1.1871 & 1.1683 & 1.1778 & 1.1444 & 1.1228 & 1.1623 & 1.2359 \\
\hline Sichuan & 0.5938 & 0.6088 & 0.5810 & 0.5784 & 0.6147 & 0.6677 & 0.7464 & 0.7067 & 0.6989 & 0.8031 & 0.8434 & 0.8620 & 0.885 & 0.8889 & 0.8685 & 0.9204 & 0.7418 \\
\hline Guizhou & 7304 & 0 & 0 & 0.7008 & 0.7357 & 0.8338 & 0.8342 & 0.8 & 0.82 & 0.9183 & 0 & 0.9 & 0.9 & 0.9 & 68 & 1 & 0.8638 \\
\hline Yunan & 0.9703 & 0.9278 & 0.9341 & 0.9223 & 0.9382 & 0.9616 & 1.0252 & 1.0207 & 1.0214 & 1.1014 & 1.1267 & 1.1084 & 1.134 & 1.1369 & 1.1832 & 1.2259 & 1.0462 \\
\hline Shaanxi & 3.4483 & 3.1881 & 3.4038 & 3.1519 & 3.4837 & 3.4627 & 3.1674 & 3.2517 & 3.1540 & 3.0267 & 2.9159 & 3.0551 & 3.3937 & 2.9105 & 2.9895 & 2.7349 & 3.1711 \\
\hline Gansu & 1.4311 & 1.3686 & 1.4118 & 1.4531 & 1.5234 & 1.5657 & 1.5490 & 1.5581 & 1.5300 & 1.5512 & 1.5379 & 1.6181 & 1.6372 & 1.6349 & 1.6559 & 1.5888 & 1.5384 \\
\hline Qinghai & 1.2647 & 1.1581 & 1.2080 & 1.7343 & 1.6592 & 1.4868 & 1.4083 & 1.3857 & 1.4291 & 1.4456 & 1.3941 & 1.5953 & 1.5464 & 1.3474 & 1.4284 & 1.5307 & 1.4389 \\
\hline Ningxia & 1.6848 & 1.9043 & 1.9094 & 1.9486 & 1.9591 & 1.9004 & 1.9838 & 1.9385 & 2.1222 & 2.2533 & 2.0456 & 1.9204 & 2.2172 & 2.2945 & 2.1518 & 2.1018 & 2.0210 \\
\hline Xinjiang & 1.5960 & 1.7353 & 1.8108 & 1.8009 & 1.7454 & 1.6249 & 1.5649 & 1.6795 & 1.8288 & 2.1223 & 2.1231 & 2.3369 & 2.2482 & 2.2396 & 2.3933 & 2.5064 & 1.959 \\
\hline
\end{tabular}

Data sources: calculating according to corresponding data.

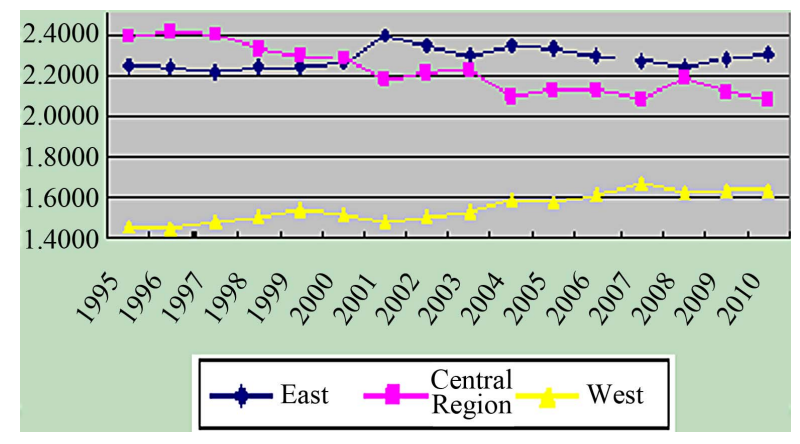

Figure 1. Changes in trends of environmental pollution emissions index.

measurement of the same individual within a certain time, which allows a certain degree of correlation between each cross-section [23]. Since each provincial data of economic development, energy consumption, environmental pollution isn't dependent, we choose to construct a panel data model and estimate by software, Eviews6.0.

The basic expression of panel data model is:

$$
\begin{gathered}
y_{i, t}=C+\alpha_{i}+\gamma_{i}+x_{i, t}^{\prime} \beta_{i}+\varepsilon_{i, t} \\
i=1,2, \cdots, N ; t=1,2, \cdots, T
\end{gathered}
$$

In the formula: $y$ is explained variable; $x$ is $k$-dimensional explanatory variable; $i$ means cross-sectional data; $t$ indicates time-series data; $\beta$ is the vector of regression coefficient; intercept term is $C+\alpha_{i}+\gamma_{i}$, among it $C$ is constant, $\alpha_{i}$ measures the differences of individuals, $\gamma_{i}$ measures differences of time $\varepsilon_{i, t}$ is stochastic error term and represents ignored impact of cross-sectional and time-varying factors in the model. According to different assumptions of intercept $\alpha_{i}$ and $\gamma_{i}$, Panel Data model 
can be divided into three basic regression models: ordinary mixed regression model, fixed-effect model and random effect model.

As Panel Data possess two-dimensional characteristics of cross-section and time-series, the model specification directly determines the effectiveness of parameter estimation. Therefore, the test of estimation model specification is essential. We introduce individual fixed-effect test and Hausman test to judge and choose model from three basic regression models. Test results are shown in Table 2.

Depend on test results, with significance level 1\%, F test reject all the null hypothesis and accept all the alternative hypothesis; so does the Hausman test. Therefore, the model specification in the paper is individual fixedeffect model.

\section{The Measurement Results}

We should accept generalized least squares method to conduct regression analysis of model (5) in order to eliminate heteroscedasticity and serial correlation that may exist in the panel data analysis. Then we establish individual fixed-effect model based on the panel data of nationwide, east, central region and west. Regression results are shown in Table $\mathbf{3}$.

From Table 3, we obtain the following results:

1) Economic scale facilitates the increase of national and western regional pollution emissions. In the condition of the other factors unchanged, when GDP increase by $1 \%$, pollution emissions will increase by $0.05 \%$ from the national angle; from the western angle, the pollution emissions will increase by $0.07 \%$ and is significantly higher than national level. Then the coefficient of east and central region is negative, indicating the pollution emissions of east and central region is gradually reducing with economic growth. In the condition of the other factors unchanged, when GDP increase by $1 \%$, from the eastern angle, pollution emissions will decrease by $0.06 \%$; from the central regional angle, pollution emissions will decrease by $0.12 \%$. Prior to 2020 , China's economy will maintain rapid growth. Therefore, the pollution emissions that result from economies of scale will be inevitable.

2) Industrial structure also exacerbates the increase of pollution emissions except that of west. The coefficient of central region do not pass the test with significance level $10 \%$, indicating that industrial structure has an unapparent effect on pollution emissions of central region. Meanwhile the coefficient of west is negative, from the angle of real situation, in the process of the industry transfer from east to west, western region has avoided the simple pollution transfer by the formulation of policy, and the pollution has been decreased. However, industrial structure of east and west has a negative effect on the decrease of pollution emissions. As the process of China's industrialization won't basically end until 2020, the increase of pollution emissions caused by industrialization tendency of industrial structure will be unavoidable.

3) Improving of trade openness is helpful to reduce pollution emissions except in east. However, only the coefficient of west passes the relevant significance test,

Table 2. Test results of model specification.

\begin{tabular}{ccccc}
\hline & Nationwide & East & Central Region & West \\
\hline F-statistic & $306.2644^{* * *}$ & $187.0185^{* * *}$ & $228.3487^{* * *}$ & $285.9415^{* * *}$ \\
Hausman test & $56.3657^{* * *}$ & $36.7642^{* * *}$ & $106.3553^{* * *}$ & $68.2051^{* * *}$ \\
\hline
\end{tabular}

Note: ${ }^{* * *},{ }^{* *},{ }^{*}$ denote that significance levels are $1 \%, 5 \%$ and $10 \%$.

Table 3. Regression results of individual fixed-effect model about factors of environmental quality in 1995-2010.

\begin{tabular}{|c|c|c|c|c|}
\hline Variables & Nationwide & East & Central Region & West \\
\hline $\mathrm{C}$ & -0.0561 & $-0.7159^{* * *}$ & 0.0069 & 0.0972 \\
\hline LnGDP & $0.0522^{* * *}$ & $-0.0585^{*}$ & $-0.1246^{* * *}$ & $0.0656^{* * *}$ \\
\hline LnSC & $0.0977^{* *}$ & $0.8231^{* * *}$ & 0.2310 & $-0.4528^{* * *}$ \\
\hline LnOPE & -0.0033 & -0.0069 & 0.0006 & $-0.0549^{* *}$ \\
\hline LnEE & $-0.1368^{* * *}$ & $0.1324^{* *}$ & $-0.0799^{*}$ & 0.0048 \\
\hline LnEP & -0.0348 & -0.0389 & $0.1363^{* *}$ & $-0.2679^{* * *}$ \\
\hline Adjusted $\mathrm{R}^{2}$ & 0.9679 & 0.9790 & 0.9553 & 0.9674 \\
\hline F-statistic & $422.4994^{* * *}$ & $531.7004^{* * *}$ & $227.6577^{* * *}$ & $337.9237^{* * *}$ \\
\hline Sample size & 448 & 160 & 128 & 160 \\
\hline
\end{tabular}

Notes: 1) estimate model by cross-section weighting and calculate robust standard deviation by cross-section SUR (PSCE); 2 ) ${ }^{* * *}$, ${ }^{* *},{ }^{*}$ denote that significance levels are $1 \%, 5 \%$ and $10 \%$. 
trade openness promote rational allocation of resources in the world, which makes China's industrial structure more reasonable and promote technological progress. In a word, the overall impact of trade openness on environment is favorable and "pollution haven hypothesis" isn't obvious in China. However, as the result of global financial crisis, it is difficult to reduce pollution emissions by improving trade openness.

4) From the national angle, improving of energy efficiency contributes to reducing pollution emissions, and its coefficient test is significant, indicating the influence is significant. However, from the regional (east, central region and west) angle, since the development stages of east, that are different, the gap of technological progress among regions still exists. Therefore, improving energy efficiency is an effective way to reduce pollution emissions.

5) Rising energy prices significantly affect reducing pollution emissions of west, when energy prices rise by $1 \%$, pollution emissions of west will reduce by $0.27 \%$. In recent years, China's reform in energy sector has achieved initial success, government regulation on energy prices has been gradually liberalized and some energy field has established market mechanism. However, due to the different process of regional marketization and differences of energy resources endowment, east whose energy resource is poor pay more attention to the relationship of input and output, when energy prices rise, these areas will make it possible to improve energy efficiency through resource allocation of market and substitution effect of technical progress.

\section{Conclusions and Revelation}

As single pollutant can hardly express the situation of environmental pollution, we propose a pollution emissions index that can reflect the level of environmental quality, measure China's 28 provinces' environmental quality from 1995 to 2010 with a dynamic objective evaluation method based on the overall differences first time, and test the impact factors on China's and regional pollution emissions index by panel data model, we get the following conclusions.

1) China's 28 provinces' pollution emissions index that is measured by dynamic objective evaluation method based on the overall differences-vertical and horizontal scatter degree method is more scientific and realistic and has the vertical and horizontal comparability. It turns out that east and central region are the major regions of China's pollution emissions, but that of central region is in a gradual downward trend; 28 provinces' pollution emissions index is greatly different and it is huge potential to reduce pollution emissions.

2) In terms of nationwide, energy efficiency, energy prices and trade openness have a negative effect on pollution emissions index. However, the impact of each variable on each region is very different.

The above conclusions imply policy implications including: 1) In line with whole national interests, when formulating pollution emissions reduction policies, governments should not only focus on national situation but also the actual situation of each region's development to develop different policies due to different regions; 2) It is the key links of reducing pollution emissions to improve energy efficiency and deepen market-oriented reforms of energy prices by straightening out property right system of resources and environment, cultivating property right trading market of resources and environment, rising the relative price and cost of energy, and gradually build pricing mechanism that can reflect resource scarcity, the relationship of market supply and demand and environmental costs, which can provide effective and lasting incentive to reduce pollution emissions.

\section{REFERENCES}

[1] H. Hettige, M. Mani and D. Wheeler, "Industrial Pollution in Economic Development: The Environmental Kuznets Curve Revisited," Journal of Development Economics, Vol. 62, No. 2, 2000, pp. 445-476. doi:10.1016/S0304-3878(00)00092-4

[2] Z. X. Zhang, "Decoupling China's Carbon Emissions Increase from Economic Growth: An Economic Analysis and Policy Implications," World Development, Vol. 28, No. 4, 2000, pp. 739-752. doi:10.1016/S0305-750X(99)00154-0

[3] W. Antweiler, B. R. Copel and M. S. Taylor, "Is Free Trade Good for the Environment," American Economic Review, Vol. 91, No. 4, 2001, pp. 877-908. doi:10.1257/aer.91.4.877

[4] D. I. Stern, "Explaining Changes in Global Sulfur Emissions: An Econometric Decomposition Approach," Ecological Economics, Vol. 42, No. 1, 2002, pp. 201-220. doi:10.1016/S0921-8009(02)00050-2

[5] S. Dinda, "Environmental Kuznets Curve Hypothesis: A Survey," Ecological Economics, Vol. 49, No. 4, 2004, pp. 431-455. doi:10.1016/j.ecolecon.2004.02.011

[6] F. X. Yang, H. L. Nie and M. Yang, "Analysis of Environmental Effects of Economic Development in China -Empirical Research Based on the Generalized Impulse Response Function," Finance and Economic Research, Vol. 36, No. 50, 2010, pp. 133-143.

[7] F. X. Yang, H. F. Ding and P. Y. Li, "The Patterns and Features Analysis of the Regional Pollution in China," Economic Geography, Vol. 30, No. 3, 2010, pp. 501-507.

[8] J.-S. Wang and C. F. He, "Energy Consumption, Economic Growth and the Changes of Carbon Dioxide Emissions," Resources and Environment of the Yangtze Basin, Vol. 19, No. 1, 2010, pp. 18-23.

[9] J. He, "The Impact of International Trade on the Environment: Industrial Sulfur Dioxide Emissions of Each 
Province in China," Economics, Vol. 9, No. 2, 2010, pp. 415-446.

[10] G. Z. Li, J. R. Jiang and C. Y. Zhou, "The Analysis of China's Environmental Pollution Factors During the Transition Period-Based on the Perspective of Total Factor Energy Efficiency," Journal of Shanxi Finance and Economics University, Vol. 31, No. 2, 2009, pp. 3239.

[11] Z. X. He and S. C. Xu, "An Empirical Study on the Impact of China's Economic Opening up on the Environment: 1997-2007," Journal of International Trade, No. 10, 2009, pp. 87-93.

[12] M. X. Yu and M. L. Zhou, "Dynamic Trends and Factors of Environmental Pollution of Each Province in China," Journal of Beijing Institute of Technology, Vol. 11, No. 4, 2009, pp. 46-49.

[13] B. Q. Lin and Z. J. Jiang, "Forecast and Factors of China's Carbon Kuznets Curve," Management World, No. 4, 2009, pp. 27-36.

[14] W. P. Yang and X. L. Yuan, "Analysis of the Impact of FDI on Environmental Pollution-Based on the Impulse Response Function Analysis of China's Time Series," World Economy Study, No. 12, 2008, pp. 62-68.

[15] F. Yu, J. G. Qi and X. L. Tian, "The Empirical Analysis of the Impact of Economic Development on Environmental Quality-Based on the Panel Data of All the China's Provinces and Cities in 1994-2004," China Industrial Economics, No. 8, 2006, pp. 36-44.

[16] G. M. Grossman and A. B. Krueger "Environmental Impacts of a North American Free Trade Agreement," Na- tional Bureau of Economic Research Working Paper, Cambridge, 1991.

[17] X. Q. Wang and F. Li, "The Relationship of Economic Growth and Environmental Pollution Levels in Tianjin," Geographical Research, Vol. 24, No. 6, 2005, pp. 834 842.

[18] F. Shen, "The Relationship of Economic Growth and Environmental Pollution in Shanghai-Based on the Empirical Analysis of Environmental Kuznets Theory," Finance and Economic Research, Vol. 34, No. 9, 2008, pp. 81-90.

[19] W. P. Yang and X. L. Yuan, "The Empirical Study of the Environmental Kuznets Hypothesis in China," Resources and Environment of the Yangtze Basin, Vol. 18, No. 8, 2009, pp. 704-710.

[20] L. Yang and X. Z. Hu, "Regional Differences and Convergence Analysis of Green Economic Efficiency in China Based on DEA," Economists, No. 2, 2010, pp. 4654.

[21] N. Shen, "Regional Spatial Analysis of Energy Inputs, Pollution Emissions and the Efficiency of Energy Economy in China," Finance \& Trade Economics, No. 1, 2010, pp. 107-113.

[22] Y. J. Guo, "Comprehensive Evaluation Theory, Methods and Applications," Science Press, Beijing, 2007.

[23] J. M. Wooldridge, "Econometric Analysis of Cross-Section and Panel Data," MIT Press, Cambridge, 2002 